\title{
Pulmonary Hypertension: A Fatal Complication of Neurofibromatosis Type 1
}

\author{
Lina Gumbiene MD, Zaneta Petrulioniene MD PhD, Kestutis Rucinskas MD PhD, \\ Vyte Maneikiene MD, Pranas Serpytis MD, Alicija Dranenkiene MD PhD, and \\ Aleksandras Laucevicius MD PhD
}

\begin{abstract}
We report a very rare case of severe pulmonary arterial hypertension in a patient with neurofibromatosis type 1 , and discuss the pathology, pathogenesis, current pulmonary hypertension classification system, and outcomes of pulmonary arterial hypertension in patients with neurofibromatosis type 1. Key words: pulmonary hypertension; neurofibromatosis. [Respir Care 2011;56(11): 1844-1848. (c) 2011 Daedalus Enterprises]
\end{abstract}

\section{Introduction}

Neurofibromatosis type 1 (von Recklinghausen disease) is a genetic disorder with an incidence of approximately 1 in 4,000 live births. It is characterized by cutaneous neurofibromas and café-au-lait spots. Other clinical manifestations include abnormalities of the cardiovascular, gastrointestinal, renal, and endocrine systems, and malignancies of the peripheral and central nervous system. ${ }^{1}$ Neurofibromatosis type 1 is associated with diffuse lung disease. ${ }^{2}$ Pulmonary hypertension associated with neurofibromatosis was included in the recently revised classification of pulmonary hypertension (Table 1 ) in the group with unclear and/or multifactorial mechanisms, ${ }^{3,4}$ because this association is very rare and very few data have been published.

The authors are affiliated with the Department of Cardiovascular Medicine, Vilnius University Hospital Santariskiu Klinikos, Vilnius University, Vilnius, Lithuania.

Dr Maneikiene presented a version of this paper at the Lithuanian national conference on pulmonary hypertension, held October 16, 2009. Dr Gumbiene presented a version of this paper at the regional conference of Vilnius cardiologists, held May 6, 2010.

The authors have disclosed no conflicts of interest.

Correspondence: Lina Gumbiene MD, Department of Cardiovascular Medicine, Vilnius University Hospital Santariskiu Klinikos, Vilnius University, Santariskiu Gatvė 2, Vilnius LT-2001 Lithuania. E-mail: lina.gumbiene@santa.lt.

DOI: $10.4187 /$ respcare. 01030

\section{Case Report}

A 30-year-old female was admitted to the cardiac intensive care unit because of severe dyspnea, progressive heart failure, and arrhythmia. Neurofibromatosis type 1 was diagnosed from her skin lesions in childhood. Glioma of the optic nerve was diagnosed at the age of 5 years. Unfortunately, glioma surgery was unsuccessful: the tumor was not removed and she went blind in one eye. Cardiac symptoms such as fatigue, palpitations, syncope, and dyspnea began at the age of 27 , after her first pregnancy and delivery, and progressed gradually. She was in World Health Organization functional class 4: breathlessness, tachypnea ( $\geq 32$ breaths/min), and tachycardia during the mildest physical exertion and at rest, even with permanent oxygen therapy. She had low blood pressure (90/60-100/70 $\mathrm{mm} \mathrm{Hg}$ ) and paroxysms of supraventricular tachycardia. She also had café-au-lait spots and cutaneous neurofibroma (Fig. 1). Her lung sounds were normal, but she had an accentuated second heart sound in the second left intercostal space and systolic tricuspid insufficiency murmur. Electrocardiogram revealed right atrial and ventricular hypertrophy. Radiograph showed a slightly enlarged pulmonary artery and right heart chambers, and a more prominent pulmonary vascularity. Echocardiography revealed dilatation of the right ventricle diastolic diameter $(2.3 \mathrm{~cm})$, right atrium $(5.0 \times 4.6 \mathrm{~cm})$, and pulmonary artery (trunk diameter $3.5-4.1 \mathrm{~cm}$ ); left-shift of the interventricular and intra-atrial septa; pericardial effusion; moderate right ventricular dysfunction (ejection fraction approximately $20 \%$, tricuspid annular plane systolic excursion $-1.2 \mathrm{~cm}$ ); moderate (grade II) tricuspid insufficiency; and 


\section{Pulmonary Hypertension: A Fatal Complication of Neurofibromatosis Type 1}

Table 1. Updated Clinical Classification of Pulmonary Hypertension

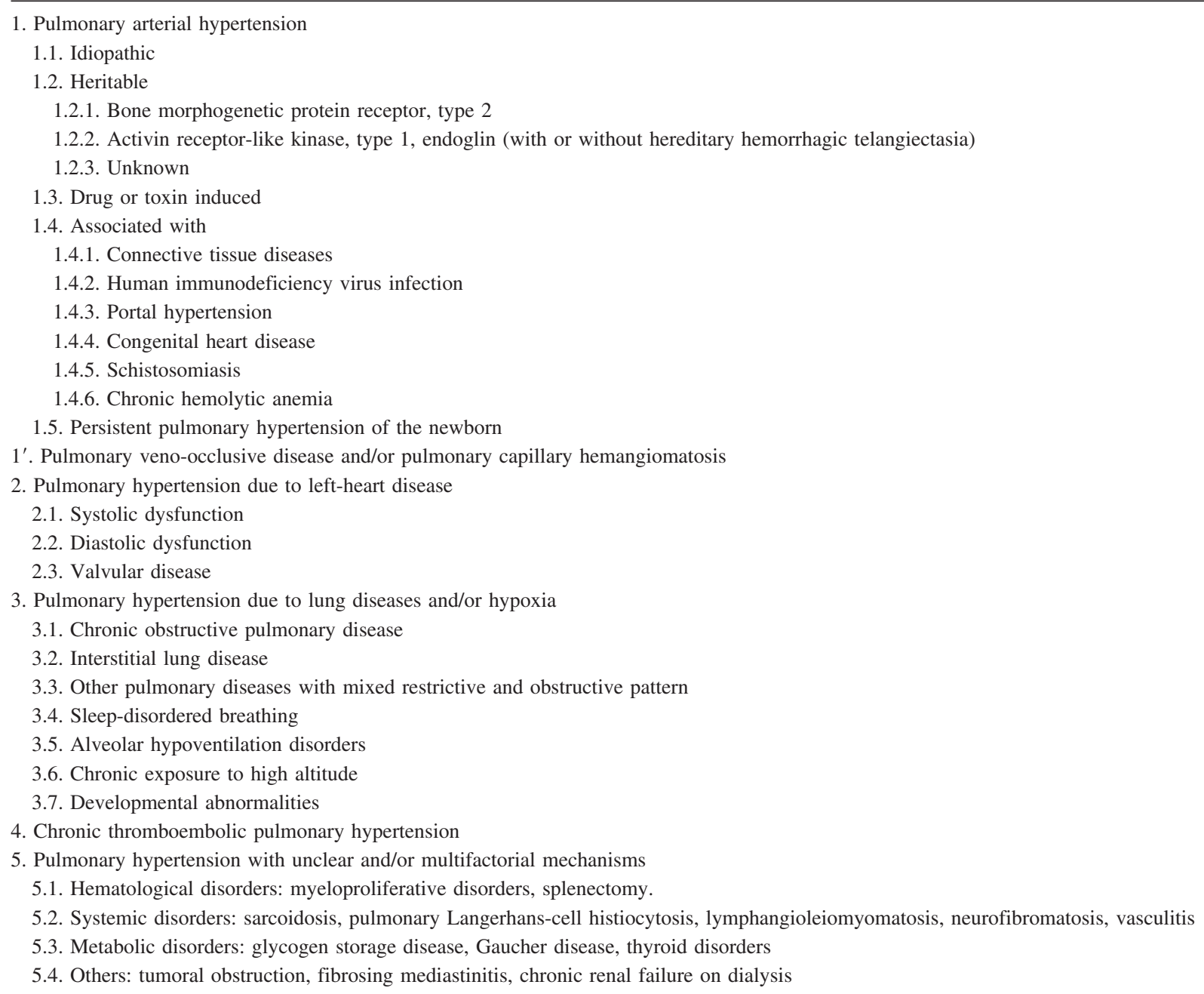

(Adapted from References 3 and 4.)

severe pulmonary hypertension (grade III, $85 \mathrm{~mm} \mathrm{Hg}$ systolic pressure difference between right ventricle and right atrium, and systolic pulmonary artery pressure was equal to systemic pressure at $100 \mathrm{~mm} \mathrm{Hg}$ ). She had slight compression of the left ventricle, caused by displacement of the intraventricular septum (left-ventricle diastolic diameter $3.9 \mathrm{~cm}$, left-ventricle systolic diameter $2.2 \mathrm{~cm}$ ), and normal left-ventricle systolic function (ejection fraction $60 \%$ ). Cardiac magnetic resonance imaging showed a rightventricular ejection fraction of $20 \%$ and good left-ventricular function. Left-heart pathology and congenital heart diseases were excluded. Respiratory function tests revealed decreased diffusing capacity of the lung for carbon monoxide $(8.9 \mathrm{mmol} / \mathrm{kPa} / \mathrm{min}, 55 \%$ of predicted); normal lung volume (total lung capacity $4.8 \mathrm{~L}, 99 \%$ of predicted); and no signs of pulmonary obstruction (FVC $3.4 \mathrm{~L}, 115 \%$ of predicted, $\mathrm{FEV}_{1} 2.97 \mathrm{~L}, 111 \%$ of predicted). High-resolu- tion computed tomogram (CT) and contrast-enhanced CT angiography showed a mosaic perfusion pattern of lung attenuation and no evidence of pulmonary disease or pulmonary embolism (Fig. 2). She had a family history of neurofibromatosis type 1 , but no family history of pulmonary hypertension. Her mother and 2 sisters had neurofibromatosis type 1 without pulmonary involvement. She had no history of sleep apnea, appetite suppressants, drug use, or toxin ingestion. We excluded antiphospholipid syndrome, collagen, thyroid, blood, and liver diseases via serology testing and ultrasound. She had a consultation with a geneticist. Unfortunately, genetic testing for neurofibromatosis type 1 and pulmonary hypertension/bone morphogenetic protein receptor 2 and others were not available. Human immunodeficiency virus testing was not performed. She underwent investigations with a neurologist and a neurosurgeon; cranial CT excluded syncope due to epilepsy. 

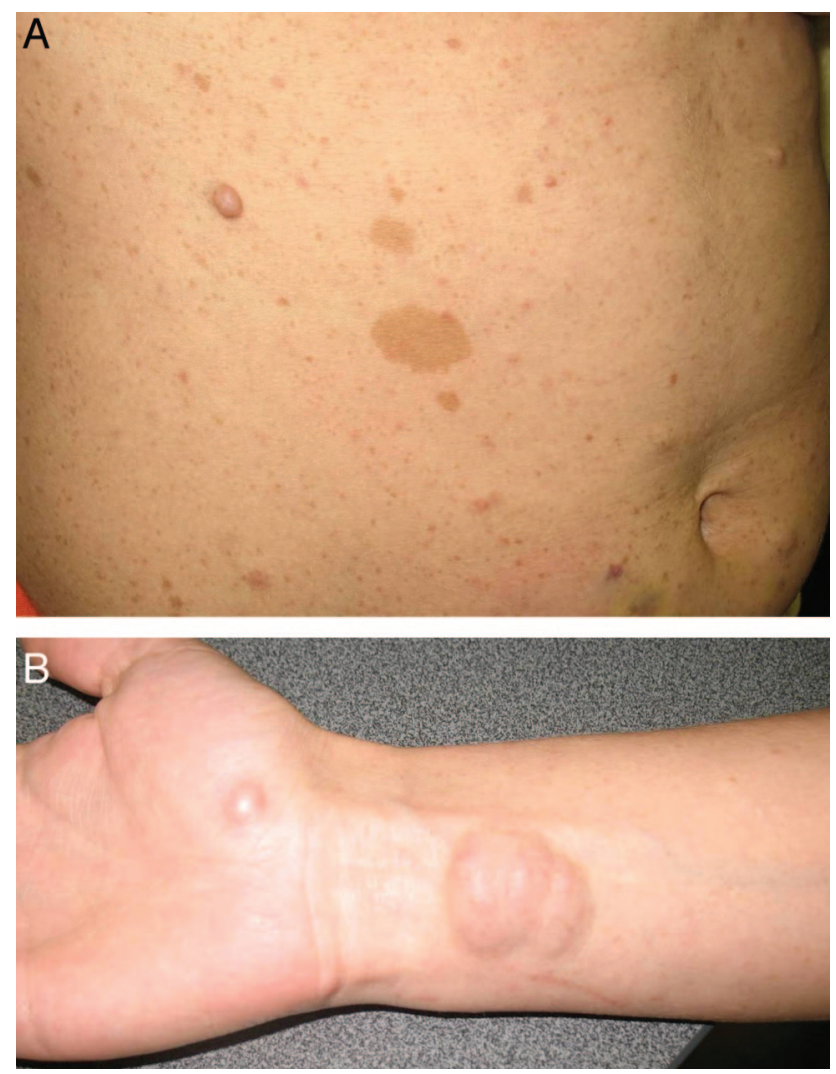

Fig. 1. Café-au-lait skin lesions and cutaneous neurofibromas on the chest, abdomen, and hand.

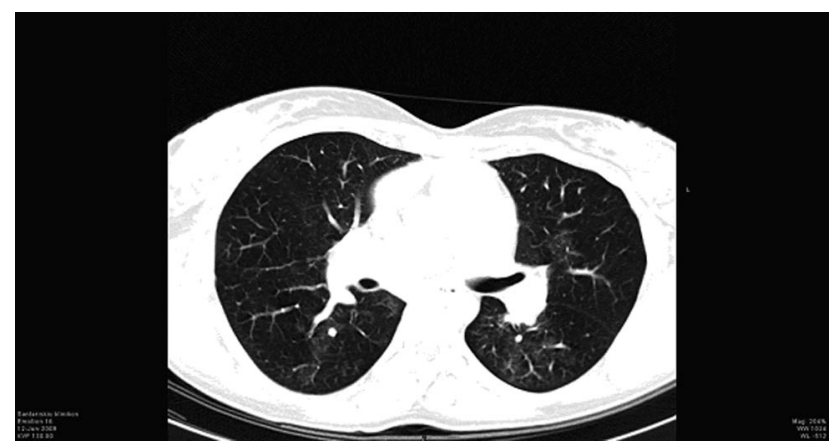

Fig. 2. Contrast-enhanced computed tomogram shows groundglass appearance and mosaic perfusion pattern of lung attenuation.

There were no indications for tumor surgery. Cardiac catheterization confirmed the diagnosis of pulmonary arterial hypertension. She had elevated mean pulmonary artery pressure (49 mm Hg, 79/32 mm $\mathrm{Hg}$ ), normal pulmonary capillary wedge pressure $(10 \mathrm{~mm} \mathrm{Hg})$, and high pulmonary vascular resistance (15 Wood units or $1,200 \mathrm{dyn} / \mathrm{s} /$ $\mathrm{cm})$. Her cardiac index was low $\left(2.49 \mathrm{~L} / \mathrm{min} / \mathrm{m}^{2}\right)$. Acute vasoreactivity test with adenosine was negative. Her hemodynamics stabilized with inotropes, oxygen therapy, di- uretics, and digoxin. Anticoagulation was initiated with heparin, and after invasive investigations warfarin was prescribed. Combination sildenafil plus bosentan was started. Amiodarone was prescribed to control arrhythmia. Her condition (no dyspnea at rest) and functional capacity improved gradually (6-min-walk distance $300 \mathrm{~m}$, maximum oxygen consumption $14.6 \mathrm{~mL} / \mathrm{kg} / \mathrm{min}$ ). She was discharged from the hospital in World Health Organization functional class 3 .

After 3 months she had a recurrence of syncope and was readmitted to our hospital. Cardiac investigation results were similar to those of the previous admission. The 6-minwalk distance was slightly improved $(310 \mathrm{~m})$. A 24-hour electrocardiogram Holter examination excluded arrhythmia as the cause of syncope. Her plasma brain natriuretic peptide remained elevated $(383 \mathrm{ng} / \mathrm{L})$. She was referred to the transplantation team. The high incidence of different malignant formations, especially after immunosuppressive therapy, in patients with neurofibromatosis type 1 and glioma was taken into account and considered a contraindication for lung and heart or lung complex transplantation. Pharmaceutical management of the pulmonary arterial hypertension was continued, but she had additional syncope episodes, dyspnea progressed, and she died. Her relatives refused an autopsy.

\section{Discussion}

Pulmonary arterial hypertension is a very rare complication of neurofibromatosis. We know of only 7 reports, which describe 12 patients. ${ }^{5-11}$ The pathological mechanism of pulmonary arterial hypertension in neurofibromatosis remains unclear, but it is hypothesized that it develops secondary to underlying vasculopathy, ${ }^{6,7,9-11}$ which is an uncommon but well recognized complication of neurofibromatosis type $1 .{ }^{11,12}$ In our patient (as in 9 of the 12 published cases) we can only make suggestions, referring to the clinical data. Our patient had a mosaic pattern of lung attenuation on CT (see Fig. 2), similar to that in other patients. ${ }^{11}$ This finding could be consistent with vasculopathy. Pulmonary plexiform lesions,${ }^{11}$ extensive irregular thickening of the intima of the pulmonary arteries by fibrous tissue, ${ }^{6}$ and medial and/or intimal hypertrophy and fibrosis of the pulmonary arteries and veins ${ }^{9}$ were found on histology. These findings confirm that vasculopathy is an important component, but the pathological mechanism could be more complex, as in pulmonary arterial hypertension associated with connective-tissue disease.

The current hemodynamic definition of pulmonary arterial hypertension is a mean pulmonary artery pressure $>25 \mathrm{~mm} \mathrm{Hg}$, a pulmonary capillary wedge pressure $\leq 15 \mathrm{~mm} \mathrm{Hg}$, and a pulmonary vascular resistance $>3$ Wood units or $240 \mathrm{dyn} / \mathrm{s} / \mathrm{cm} \cdot{ }^{13}$ Our patient and all the previously published cases met those criteria. Recent Eu- 
ropean guidelines for pulmonary hypertension, ${ }^{4}$ with reference to updated clinical classification of pulmonary hypertension by Simmenneau and coauthors, ${ }^{3}$ however, did not include this pathology in the pulmonary-arterial-hypertension group. Pulmonary hypertension associated with neurofibromatosis was included (see Table 1) in the group with unclear and/or multifactorial mechanisms. Lung fibrosis and chronic thromboembolic pulmonary hypertension are thought to play a role. ${ }^{3}$ This leads to confusion about diagnosis (pulmonary arterial hypertension as a separate disease versus complication of neurofibromatosis type 1) and treatment (indications for specific pulmonary arterial hypertension therapy). The malignant clinical course and poor prognosis for the combination of generally benign neurofibromatosis type 1 and pulmonary hypertension is similar to other disorders associated with pulmonary arterial hypertension. Despite the rarity of this pathology and the paucity of data, it seems that pulmonary arterial hypertension develops secondary to underlying neurofibromatosis type 1 and should be managed as associated pulmonary arterial hypertension. The association of neurofibromatosis type 1 and pulmonary hypertension is real and should be acknowledged by international societies.

Specific pulmonary vasodilators approved for pulmonary arterial hypertension treatment improve the clinical condition and pulmonary hemodynamics of patients with neurofibromatosis type 1 and pulmonary hypertension. Most such patients have been treated with epoprostenol. Bosentan and sildenafil were also effective. Two patients were treated with calcium-channel blockers. Interestingly, one of them, a 70-year-old male with moderate pulmonary arterial hypertension (mean pulmonary artery pressure $50 \mathrm{~mm} \mathrm{Hg}$, pulmonary vascular resistance $570 \mathrm{dyn} / \mathrm{s} / \mathrm{cm}$ ), survived for 6 years. ${ }^{11}$ These patients seems to have a similar heterogeneous response to vasoreactivity testing: the positive responders have a better prognosis, the same as patients with idiopathic pulmonary arterial hypertension. Indeed, despite the treatment, 7 of 8 patients (including our patient) died within 1-6 years. Pulmonary endarterectomy was performed only on the surviving patient ${ }^{6}$ and partially improved that patient's pulmonary hypertension, though no evidence of thrombi was found during surgery. The value of pulmonary endarterectomy in patients without pulmonary thromboembolism remains unclear. Follow-up data from the other 5 patients ${ }^{5,7,9,10}$ was not published.

The last step in the management of patients with advanced pulmonary arterial hypertension is lung transplantation. About $20 \%$ of the patients with neurofibromatosis type 1 had central-nervous-system tumors. ${ }^{14} \mathrm{~A}$ dual diagnosis of neurofibromatosis type 1 and optic glioma is the critical factor for central-nervous-system tumor development, ${ }^{15}$ so this treatment modality was contraindicated for our patient and hardly possible for other patients with such pathology. Neurofibromatosis type 1 on its own is not a contraindication for transplantation, and successful lung transplantations in patients with neurofibromatosis type 1 have been reported. ${ }^{16}$ However, transplant clinicians should carefully weigh the potential risk of cancer in deciding candidacy for transplantation, because there is a high incidence of malignant formations with immunosuppressive therapy in neurofibromatosis type $1 .{ }^{16}$

Early recognition of pulmonary arterial hypertension is very important for patient survival. ${ }^{4,13}$ However, routine echocardiography or pulmonary function testing screening of neurofibromatosis type 1 patients is not recommended because of the very low incidence of pulmonary arterial hypertension or diffuse lung diseases (5.5\%). ${ }^{2}$ Investigations for pulmonary hypertension should be performed immediately if a patient with neurofibromatosis type 1 develops signs or symptoms that suggest pulmonary hypertension, such as dyspnea, syncope, fatigue.

\section{REFERENCES}

1. Reynolds RM, Browning GG, Nawroz I, Campbell IW. Von Recklinhausen's neurofibromatosis: neurofibromatosis type 1. Lancet 2003;361(9368):1552-1554.

2. Zamora AC, Collard HR, Wolters PJ, Webb WR, King TE. Neurofibromatosis-associated lung disease: a case series and literature review. Eur Respir J 2007;29(1):210-214.

3. Simonneau G, Robbins I, Beghetti M, Channick RN, Delcroix M, Denton CP, et al. Updated clinical classification of pulmonary hypertension. J Am Coll Cardiol 2009;54(Suppl 1):S43-S54.

4. Galie N, Hoeper MM, Humbert MJC, Torbicki A, Vachiery J-L, Barbera JA, et al; The Task Force for the Diagnosis and Treatment of Pulmonary Hypertension of the European Society of Cardiology and the European Respiratory Society, endorsed by the International Society of Heart and Lung Transplantation. Guidelines for the diagnosis and treatment of pulmonary hypertension. Eur Heart J 2009; 30(20):2493-2537.

5. Porterfield JK, Pyeritz RE, Traill TA. Brief clinical report: pulmonary hypertension and interstitial fibrosis in von Recklinghausen neurofibromatosis. Am J Med Genet 1986;25(3):531-535.

6. Samuels N, Berkman N, Milgalter E, Bar-Ziv J, Amir G, Kramer M. Pulmonary hypertension secondary to neurofibromatosis: intimal fibrosis versus thromboembolism. Thorax 1999;54(9):858-859.

7. Aoki Y, Kodama M, Mezaki T, Ogawa R, Sato M, Okabe M, et al. Von Recklinghausen disease complicated by pulmonary hypertension. Chest 2001;119(5):1606-1608.

8. Hernandez FJG, Ronan JS, Medina CO, Romero LM. [Hipertension arterial pulmonary primaria en un paciente con neurofibromatosis]. Med Clin (Barc) 2002;118(2):78-79. Article in Spanish.

9. Simenoni S, Puccetti A, Chilosi M, Tinazzi E, Prati D, Corrocher R, et al. Type 1 neurofibromatosis complicated by pulmonary artery hypertension: a case report. J Med Invest 2007;54(3-4):354-358.

10. Engel PJ, Baughman RP, Menon SG, Kereiakes DJ, Taylor L, Scott M. Pulmonary hypertension in neurofibromatosis. Am J Cardiol 2007; 99(8):1177-1178.

11. Stewart DR, Cogan JD, Kramer MR, Miller WT, Christiansen LE, Pauciulo MW, et al. Is pulmonary arterial hypertension in neurofibromatosis type 1 secondary to a plexogenic arteriopathy? Chest 2007;132(3):798-808. 


\section{Pulmonary Hypertension: A Fatal Complication of Neurofibromatosis Type 1}

12. Hamilton SJ, Friedman JM. Insights into the pathogenesis of neurofibromatosis 1 vasculopathy. Clin Genet 2000;58(5):341-344.

13. McLaughlin VV, Archer SL, Badesch DB, Barst RJ, Farber HW, Linder JR, et al. ACCF/AHA 2009 expert consensus document on pulmonary hypertension: a report of the American College of Cardiology Foundation Task Force on Expert Consensus Documents and the American Heart Association developed in collaboration with the American College of Chest Physicians; American Thoracic Society; and the Pulmonary Hypertension Association. J Am Coll Cardiol 2009;53(17):1573-1619.
14. Rosenfeld A, Listernick R, Charriw J, Goldman S. Neurofibromatosis type 1 and high-grade tumors of the central nervous system. Childs Nerv Syst 2010;26(5):663-667.

15. Singhal S, Birch JM, Kerr B, Lashford L, Evans DGR. Neurofibromatosis type 1 and sporadic optic gliomas. Arch Dis Child 2002; 87(1):65-70.

16. Merlo CA, Studer SM, Conte JV, Yang SC, Sonnett J, Orens JB. The course of neurofibromatosis type 1 on immunosuppression after lung transplantation: report of 2 cases. J Heart Lung Transplant 2004; 23(6):774-776 